\title{
Enterocolic fistula: A rare presentation of cytomegalovirus infection
}

\author{
Richdeep S Gill MD¹, Geoffrey Taylor MD FRCPC FACP2 ${ }^{2}$, Robert M Penner MD FRCPC ${ }^{2}$, Sarvesh Logsetty MD 3
}

RS Gill, G Taylor, RM Penner, S Logsetty. Enterocolic fistula: A rare presentation of cytomegalovirus infection. Can J Infect Dis Med Microbiol 2012;23(2):e41-e43.

In the present report, the first reported case of cytomegalovirus (CMV)associated enterocolic fistula in an HIV/AIDS patient is described. CMV colitis is the second most common presentation of CMV infection in immunocompromised patients. CMV-associated enteric fistulae are an exceedingly rare complication, with only four previous cases described: a gastrocolic, an enterocutaneous, a rectovaginal and a colocutaneous fistula. Management of these patient demonstrates the importance of treating the precipitating viral infection before considering surgical intervention of the enterocolic fistula.

Key Words: AIDS; CMV colitis; CMV infection; Fistula

\section{La fistule entérocolique : une rare présentation de l'infection par le cytomégalovirus}

\begin{abstract}
Dans le présent rapport, les auteurs décrivent le premier cas déclaré de fistule entérocolique associée au cytomégalovirus (CMV) chez un patient atteint du VIH-sida. La colite à CMV est la deuxième présentation en importance d'infection par le CMV chez les patients immunodéprimés. Les fistules entériques liées au CMV représentent une complication extrêmement rare puisque seulement quatre cas ont déjà été décrits : une fistule gastrocolique, une fistule entérocutanée, une fistule rectovaginale et une fistule colocutanée. La prise en charge de ce patient démontre l'importance de traiter l'infection virale déclencheuse avant d'envisager une intervention chirurgicale de la fistule entérocolique.
\end{abstract}

$\mathrm{C}$ ytomegalovirus (CMV) is a common herpes virus (1), which can present with clinically significant disease in immunocompromised patients (2). In persons living with HIV, CMV colitis is the second most common presentation of CMV infection following CMV retinitis (3). Severe CMV colitis can manifest as bloody diarrhea and progress to bowel perforation. Although described in the literature, CMV-related enteric fistula are exceedingly rare, with only four previous reports (4-7): a gastrocolic fistula secondary to perforation, an enterocutaneous fistula from the rectum, a rectovaginal fistula and a colocutaneous fistula. In the present report, we describe the first case of CMV infection presenting as an enterocolic fistula in an HIVpositive patient.

\section{CASE PRESENTATION}

A 36-year-old HIV-positive man on no antiretroviral therapy with a $\mathrm{CD}^{+}$count of $10 \times 10^{6} / \mathrm{L}$ ( $2 \%$ of total lymphocytes) presented with a two-month history of worsening diarrhea and abdominal pain. The patient reported a one-week history of fever and chills on presentation. There was no evidence of peritonitis on physical examination. His medical history was significant for an initial diagnosis of HIV one year earlier when he presented with Pneumocystis jirovici pneumonia, which was successfully treated, but he was then lost to follow-up. $\mathrm{He}$ returned four months later with bloody diarrhea and was found to have endoscopy- and biopsy-confirmed CMV colitis. He was prescribed a brief course of intravenous ganciclovir followed by oral valganciclovir but failed to return for follow-up.

Given his systemic illness, intravenous ganciclovir treatment was reinitiated and a colonoscopy was arranged. In the sigmoid colon, at a distance of $25 \mathrm{~cm}$ from the anal verge, an enterocolic fistula was encountered (Figure 1). The colonoscope could be passed either more proximally into the colon or into one of the proximal or distal limbs of the small bowel. Solid stool remained in the proximal colon, despite the use of an oral preparatory solution, indicating a probable bypass of that segment of colon. Despite deep endoscopy of the small bowel in both directions, no anatomical landmarks, such as the ileocecal valve, were encountered to confirm the anatomical location. No masses suggestive of neoplasm were present at the fistula site. Multiple biopsies were taken. No evidence of mycobacterial infection was demonstrated on biopsy with Ziehl-Neelsen staining and mycobacterial culture; however, inflammatory infiltrate was observed. A subsequent computed tomography (CT) scan confirmed an inflammatory mass in the lower abdomen (Figure 2).

The patient's condition improved with intravenous ganciclovir, and a sigmoidoscopy was performed to confirm etiology. Successive biopsies revealed colonic mucosa adjacent to small bowel mucosa, with evidence of focal erosive colitis. Multiple CMV intranuclear inclusions were identified predominantly in the granulation tissue and inflammatory infiltrate. No evidence of lymphoid malignancy or mycobacterium was verified. Principles for management of a fistula in the setting of an inflammatory mass were followed (8). The patient was malnourished, and he was provided with supplemental nutrition. A discussion was held regarding the role of surgical resection. Bowel resection in the setting of an actively inflamed mass is difficult and has a high potential for complications, including enterotomies, anastomotic dehiscence and ureteric injury $(9,10)$. Given the location of the fistula and the significant inflammation, immediate surgery would also have mandated a stoma, with delayed reversal, once the inflammation was reduced. Rather than embark on this possibly complicated path, the decision was made to reassess the situation after the ganciclovir had reduced the inflammation. Arrangements were made for outpatient ganciclovir therapy once the initial acute colitis had settled.

The patient's condition gradually improved with ganciclovir therapy, and he was gaining weight and tolerating oral intake with only four to five bowel movements a day. At this point, a discussion regarding elective surgery was held with the patient. He was reluctant to proceed with an operation, especially when he was advised that there would still be a small but real possibility of requiring a stoma if the bowel could not be anastamosed satisfactorily. As such, the

${ }^{1}$ Department of Surgery; ${ }^{2}$ Department of Medicine, University of Alberta, Edmonton, Alberta; ${ }^{3}$ Department of Surgery, University of Manitoba, Winnipeg, Manitoba

Correspondence: Dr Richdeep S Gill, Department of Surgery, University of Alberta, 9-50 Medical Sciences Building, Edmonton, Alberta T6G 2M7.

Telephone 780-492-3159, fax 780-407-3283, e-mail richdeep@ualberta.ca 

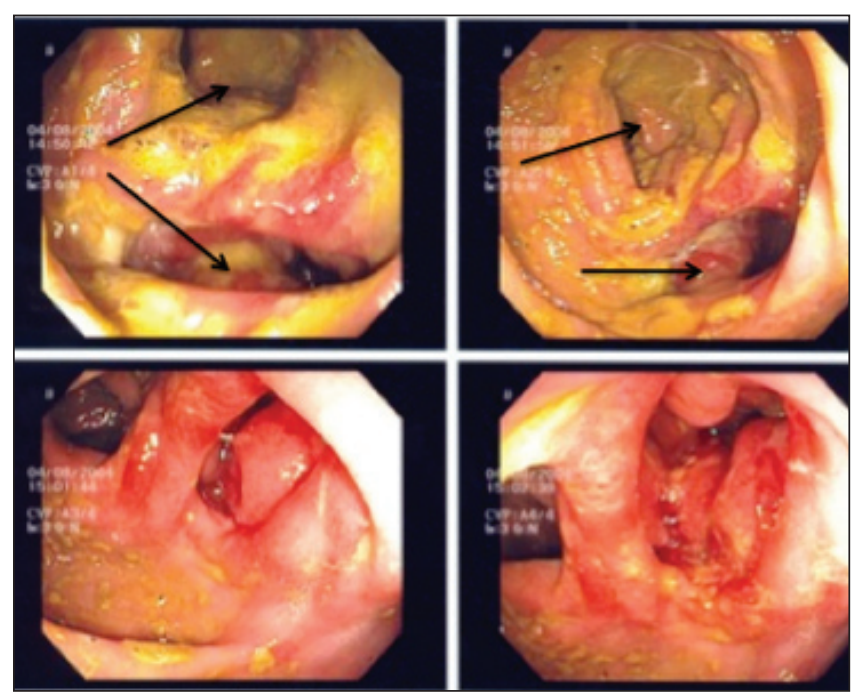

Figure 1) Colonoscopy demonstrating multiple fistula tracts (marked by black arrows)

decision was made with the patient to continue conservative management.

Following completion of induction therapy with intravenous ganciclovir (21 days), maintenance therapy was continued with oral valganciclovir (900 mg daily). Antiretroviral therapy was introduced (initially lopinavir/ritonavir, lamivudine and tenofovir, later changed to atazanavir, ritonavir and emtracitabine/tenofovir). Over the next eight years, antiretroviral treatment was maintained. Plasma HIV RNA levels fell from a baseline of 730,000 copies $/ \mathrm{mL}$ to undetectable levels $(<50$ copies $/ \mathrm{mL})$ within six months and was maintained at that level on serial monitoring. The $\mathrm{CD}^{+} \mathrm{T}$ lymphocyte cell count progressively rose from $10 \times 10^{6} / \mathrm{L}$ and $2 \%$ of total lymphocytes at presentation to $450 \times 10^{6} / \mathrm{L}$ and $27 \%$ of total lymphocytes after four years of antiretroviral therapy. Maintenance valganciclovir was discontinued after two years of antiretroviral therapy when the $\mathrm{CD}^{+}{ }^{+}$count was consistently higher than $100 \times 10^{6} / \mathrm{L}$. No clinical evidence of relapse of colitis occurred following discontinuation of valganciclovir. Diarrhea continued to be controlled with intermittent use of antimotility therapy (Imodium, Johnson \& Johnson Inc, USA) and the patient averaged six semiformed bowel movements per day with little or no need for nocturnal bowel movements. After one year of antiretroviral and anti-CMV therapy, the patient's baseline weight of $59 \mathrm{~kg}$ had risen to $70 \mathrm{~kg}$ and subsequently fluctuated between $67 \mathrm{~kg}$ (body mass index $\left.24 \mathrm{~kg} / \mathrm{m}^{2}\right)$ and $88 \mathrm{~kg}$.

\section{DISCUSSION}

CMV is a common herpes virus, for which $>50 \%$ of the world's population is seropositive (11). It is also the most common opportunistic viral infection in immunocompromised patients (3). This includes patients with HIV/AIDS, organ transplantation and those receiving chemotherapy. The two most common presentations are CMV retinitis and colitis (3). Gastrointestinal manifestations of CMV colitis can present with abdominal pain, ulceration, bleeding and watery diarrhea (12). A CMV lesion can also result in perforating ileocolitis, hemorrhagic proctocolitis and toxic megacolon requiring emergent surgical intervention $(13,14)$.

CMV colitis can be visualized by colonoscopy; however, diagnosis of CMV is made histologically $(15,16)$. The presence of giant cells with intranuclear and intracytoplasmic inclusions provides confirmation of colonoscopic suspicion of CMV. The CMV inclusions are deemed significant when they are associated with mucosal ulcers, necrotic foci and acute inflammatory infiltrates (15). As with the present case, biopsies demonstrated intranuclear inclusions at the site

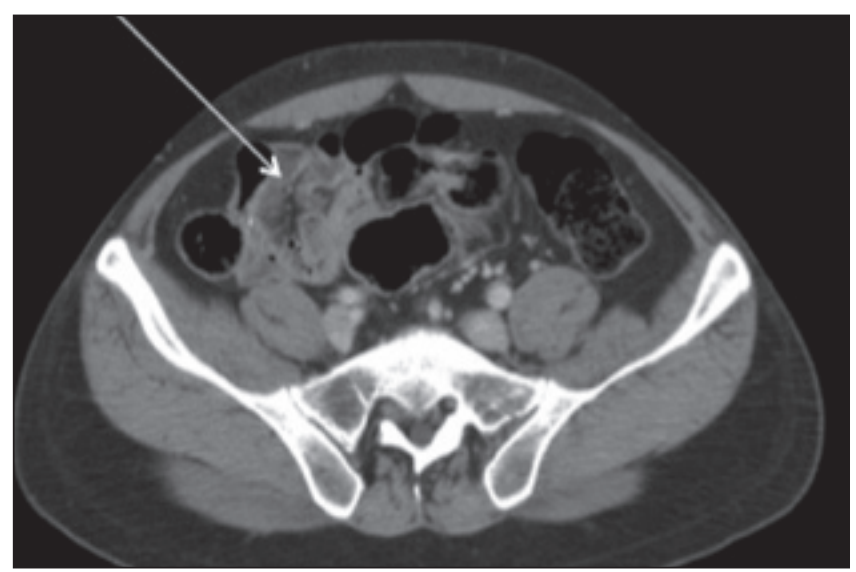

Figure 2) Computed tomography scan of the abdomen with inflammatory infiltrate in the right lower quadrant (marked by white arrow)

of the enterocolic fistula. Before diagnosis of CMV-associated fistula, more common etiologies such as lymphoma and tuberculosis were investigated and ruled out. No confirmatory endoscopic or histological evidence of either was present.

The present case is the first report of enterocolic fistula resulting from CMV colonic infection in an immunocompromised patient. The rectosigmoid region involved is the most common site for CMV colitis (17); however, only an enterocutaneous fistula and rectovaginal fistula near this site had been previously reported $(5,7)$. The present patient's noncompliance with ganciclovir treatment over the course of his illness may have been contributory. We speculate that partial healing with relapsing active disease may have predisposed him to fistula formation. Based on the present case, we state that it is important to recognize the possibility of enteric fistulae compounding CMV colitis. We conversely recognize that enteric fistula presenting within an immunocompromised host may be CMV-related. This appreciation enables appropriate treatment of the viral infection before considering surgical management of CMV-associated fistula.

\section{REFERENCES}

1. Nankervis GA, Kumar ML. Diseases produced by cytomegaloviruses. Med Clin North Am 1978;62:1021-35.

2. Dieterich DT. Cytomegalovirus: A new gastrointestinal pathogen in immunocompromised patients. Am J Gastroenterol 1987;82:764-5.

3. Peters BS, Beck EJ, Anderson S, et al. Cytomegalovirus infection in AIDS. Patterns of disease, response to therapy and trends in survival. J Infect 1991;23:129-37.

4. Aqel NM, Tanner P, Drury A, Francis ND, Henry K.

Cytomegalovirus gastritis with perforation and gastrocolic fistula formation. Histopathology 1991;18:165-8.

5. Borum ML. Cytomegalovirus infection causing an enterocutaneous fistula in a patient with acquired immunodeficiency syndrome. Dig Dis Sci 1997;42:2603-5.

6. Dumoulin A, Boulmerka H, Tran Van Nhieu J, Lang P, Baron C. Severe recurrent cytomegalovirus disease revealed by a colocutaneous fistula in a kidney transplant recipient. Transpl Infect Dis 2003;5:147-50.

7. Zaragoza A, Viciano V, Roca MJ, et al. Cytomegalovirus colitis and recto-vaginal fistula in an immunocompetent women. Rev Esp Enferm Dig 2002;94:778-80.

8. Schecter WP, Hirshberg A, Chang DS, et al. Enteric fistulas: Principles of management. J Am Coll Surg 2009;209:484-91.

9. Peppas G, Bliziotis IA, Oikonomaki D, Falagas ME. Outcomes after medical and surgical treatment of diverticulitis: A systematic review of the available evidence. J Gastro Hepatol 2007;22:1360-68.

10. Aydin HN, Remzi FH. Diverticulitis: When and how to operate? Dig Liver Dis 2004;36:435-45.

11. Starr SE. Cytomegalovirus. Pediatr Clin North Am 1979;26:283-93. 
12. Buckner FS, Pomeroy C. Cytomegalovirus disease of the gastrointestinal tract in patients without AIDS. Clin Infect Dis 1993;17:644-56.

13. Orloff JJ, Saito R, Lasky S, Dave H. Toxic megacolon in cytomegalovirus colitis. Am J Gastroenterol. 1989;84:794-7.

14. Wexner SD, Smithy WB, Trillo C, Hopkins BS, Dailey TH. Emergency colectomy for cytomegalovirus ileocolitis in patients with the acquired immune deficiency syndrome. Dis Colon Rectum 1988;31:755-61.
15. Drew WL. Diagnosis of cytomegalovirus infection. Rev Infect Dis 1988;10(Suppl 3):S468-76.

16. Drew WL. Cytomegalovirus infection in patients with AIDS. J Infect Dis 1988;158:449-56.

17. Dieterich DT, Rahmin M. Cytomegalovirus colitis in AIDS: Presentation in 44 patients and a review of the literature. J Acquir Immune Defic Syndr 1991;4(Suppl 1):S29-35. 


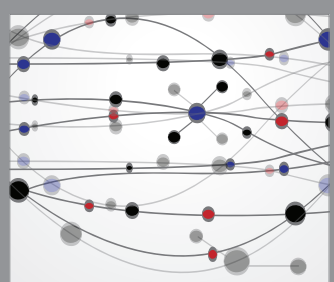

The Scientific World Journal
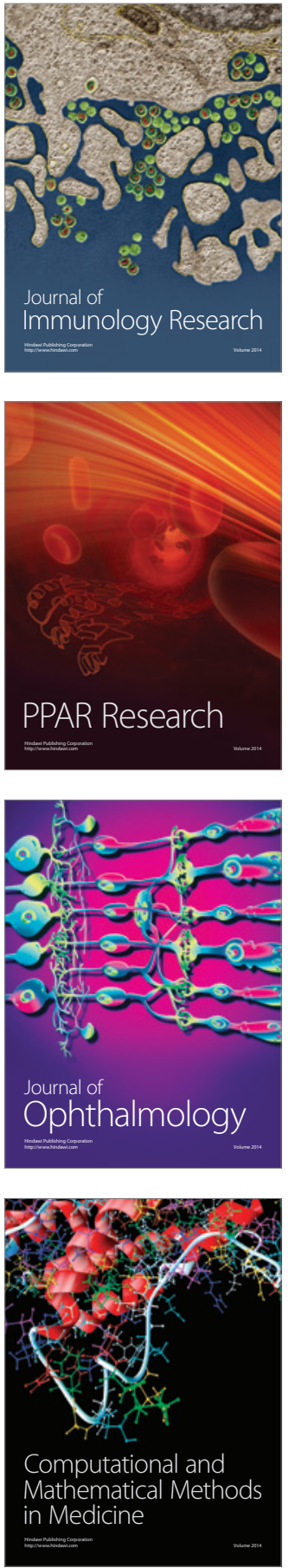

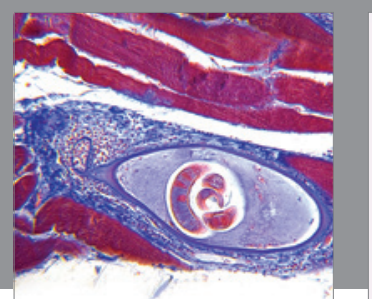

Gastroenterology Research and Practice

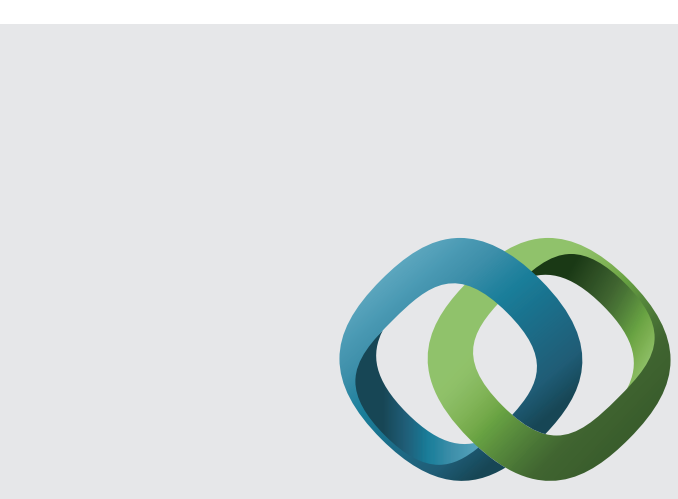

\section{Hindawi}

Submit your manuscripts at

http://www.hindawi.com
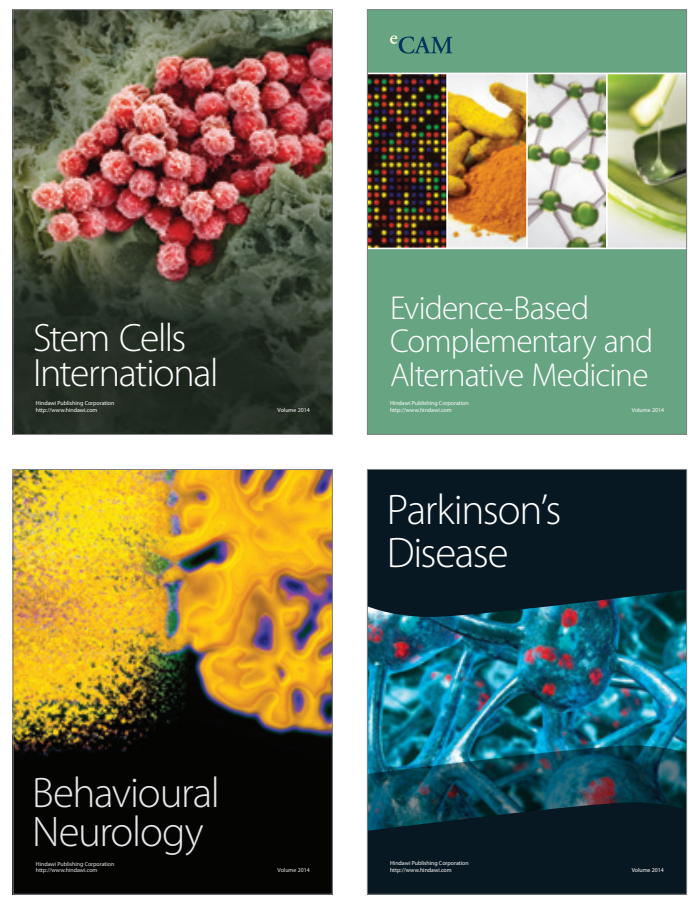
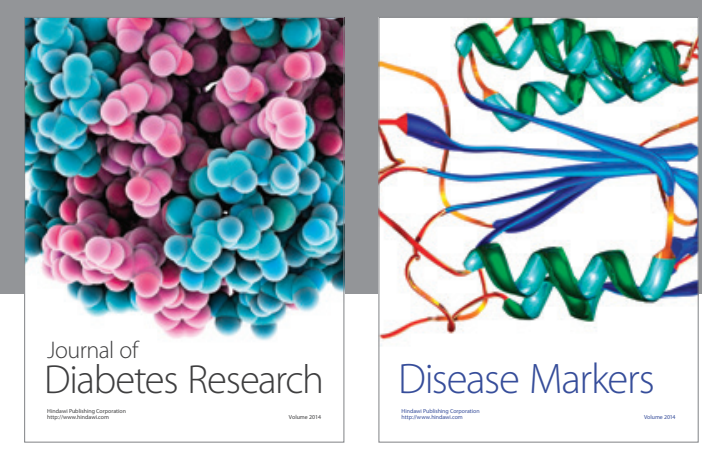

Disease Markers
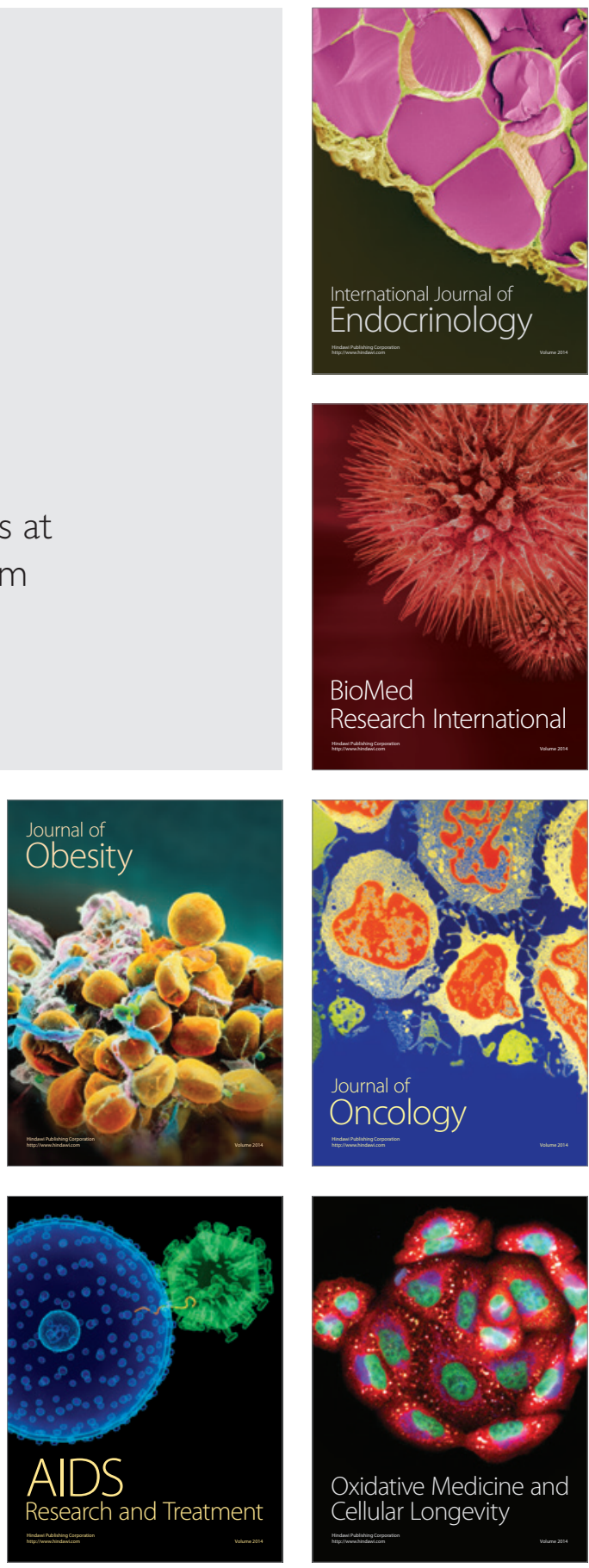